JOURNAL OF PUBLIC HEALTH INOVATION

VOL. 02. NO. 01, DESEMBER 2021

DOI: $10.34305 /$ iphi.v2i1.345
Ciptaan disebarluaskan di bawah

Lisensi Creative Commons Atribusi-

NonKomersial-BerbagiSerupa 4.0

\title{
ANALISIS FAKTOR YANG BERHUBUNGAN DENGAN KINERJA KADER KESEHATANTUBERKULOSIS DI KABUPATEN KUNINGAN PADA SAAT PANDEMI COVID-19 TAHUN 2020
}

\author{
Sultonnur Rosid, Fitri Kurnia Rahim, Fuad Hilmi Sudasman \\ STIKes Kuningan \\ sulton@pintarword.com
}

\begin{abstract}
Abstrak
Tuberkulosis menjadi penyakit no.2 mematikan di dunia, maka perlu upaya strategi penyelesaian penyakit tersebut. Salah satunya program kemenkes RI yaitu Eliminasi TB 2030 yang meliputi penemuan aktif, kemitraan dan mobilisasi sosial (kegiatan investigasi kontak serta Penyuluhan TB) yang dilakukan oleh kader. Pada tahun 2020 di Kuningan ada 1.009 IK, menurun dibanding tahun 2019 ada 1.720 IK yang dilaporkan. Kinerja kader mengalami penurunan karena dilihat dari jumlah kasus TB di Kabupaten Kuningan masih sebanyak 2.504 kasus yang diperkirakan hanya ditemukan sekitar $65.63 \%$ terduga kasus. Maka daripada itu perlu dilakukan penelitian untuk menganalisis faktor yang berhubungan dengan Kinerja Kader Kesehatan Tuberkulosis di Kabupaten Kuningan pada pada saat pandemi COVID-19 tahun 2020 .

Jenis penelitian ini adalah penelitian kuantitatif dengan pendekatan korelasional. Desain yang digunakan dalam penelitian ini menggunakan desain cross-sectional. Populasi dan sampel pada penelitian ini adalah kader kesehatan TB Kabupaten Kuningan sebanyak 65 orang kader (total sampling). Pengumpulan data dilakukan dengan mengisi kuesioner dan lembar kinerja melalui wawancara. Analisis data menggunakan uji chi-square dan rank spearman.

Sebanyak 64.6\% kader memiliki kinerja yang kurang baik. Hasil uji hipotesis menunjukkan terdapat hubungan antara kinerja dengan umur $(P=0.003)$, masa kerja ( $P=0.001)$, motivasi $(P=0.010)$ dan sikap $(P=0.001)$. Kemudian tidak terdapat hubungan yang signifikan antara kinerja dengan status pekerjaan $(P=0.375)$ dan pendidikan $(P=0.098)$.

Tidak ada hubungan antara umur, pendidikan dan status pekerjaan dengan Kinerja kader. Adanya hubungan antara masa kerja, motivasi dan sikap dengan kinerja kader
\end{abstract}


JOURNAL OF PUBLIC HEALTH INOVATION

VOL. 02. NO. 01, DESEMBER 2021

DOI: $10.34305 /$ iphi.v2i1.345
Ciptaan disebarluaskan di bawah

Lisensi Creative Commons Atribusi-

NonKomersial-BerbagiSerupa 4.0

kesehatan. Perlu dilakukan pemeliharaan dan memotivasi kader kesehatan agar dapat meningkatkan kinerjanya, seperti penyegaran pengetahuan kader.

Kata kunci $\quad$ : Kinerja, Karakteristik, Motivasi, Sikap

Pendahuluan

Tuberkulosis (TB) merupakan penyakit menular yang menjadi penyebab utama buruknya kesehatan di dunia. Pada tahun 2019, sekitar 10 juta orang menderita penyakit TB dan 1,4 juta meninggal karena TB. Indonesia berada pada peringkat ke-2 yang menyumbang kasus TB terbanyak di dunia, yaitu sebanyak $8,5 \%$ dari total kasus di dunia (World Health Organization, 2020).

Kementerian kesehatan melalui Dirjen Pencegahan dan Pengendalian Penyakit Menular (P2PM) membuat beberapa tahapan dalam program Eliminasi Tuberkulosis 2030. Untuk mencapai eliminasi TB 2030 ini tidak terlepas dari kinerja kader melalui beberapa kegiatan, diantaranya yaitu melakukan penemuan intensif, penemuan aktif, penemuan masif, serta kemitraan dan mobilisasi sosial dengan langkah Penguatan Public Private Mix (PPM), kemitraan jajaran pemerintah dan swasta (Dirjen Pencegahan dan Pengendalian Penyakit, 2020).
Hasil kinerja kader yang dilihat dari jumlah KK di Provinsi Jawa Barat pada tahun 2019, kasus Tuberkulosis yang dilaporkan sebanyak 109.463 kasus, meningkat $30,07 \%$ dibandingkan tahun 2018 yaitu sebesar 76.546 kasus (Dinas Kesehatan Jawa Barat, 2020). Kinerja kader kesehatan TB di Kabupaten Kuningan tidak terlalu baik. Dilihat dari jumlah kasus TB di Kabupaten Kuningan masih banyak, diperkirakan masih ada 2.504 kasus. Berdasarkan data bagian P2PM Dinkes Kabupaten Kuningan dari 2.504 kasus yang diperkirakan, sudah ditemukan sekitar $65.63 \%$ kasus, sebanyak 626 terduga kasus diantaranya adalah hasil kinerja kader (Dinas Kesehatan Kabupaten Kuningan, 2020).

Berdasarkan hasil penelitian sebelumnya ada beberapa faktor yang mempengaruhi kinerja kader kesehatan diantaranya umur $(\mathrm{P}=0.004)$, pendidikan $(\mathrm{P}=0.003)$ dan pekerjaan $\quad(\mathrm{P}=0.000)$ (Hanum, F., \& Yanuarita, 2020; Rinayati et al., 2020). 
JOURNAL OF PUBLIC HEALTH INOVATION

VOL. 02. NO. 01, DESEMBER 2021

DOI: $10.34305 /$ jphi.v2i1.345
Ciptaan disebarluaskan di bawah

Lisensi Creative Commons Atribusi-

NonKomersial-BerbagiSerupa 4.0 Internasional.
Kemudian hasil penelitian lain mengemukakan bahwa terdapat hubungan antara motivasi dengan kinerja seorang kader $(\mathrm{P}-$ Value $=0.002)$. Karena dorongan yang kuat akan membuat pengabdian dan menambah pengalaman semakin besar, memiliki semangat dalam bekerja, adanya pemberian penghargaan terhadap prestasi dan lingkungan pekerjaan yang baik (A'maliyah \& Wahyono, 2021; Coenraad et al., 2020). Pada tahun 2020 terjadi pandemi COVID-19 yang mengharuskan seluruh wilayah jawa memberlakukan Pembatasan Sosial Berskala Besar (PSBB) oleh pemerintah. Diberlakukannya PSBB berdampak pada sikap kader dalam melakukan kegiatan investigasi kontak dan penyuluhan.

Berdasarkan fakta dari beberapa sumber data, referensi penelitian dan kondisi pandemi di tahun 2020, peneliti ingin melakukan penelitian mengenai analisis faktor yang berhubungan dengan kinerja kader kesehatan TB di Kabupaten Kuningan pada saat pandemi COVID-19.

\section{Metode}

Penelitian ini menggunakan metode deskriptif korelasional. Desain yang digunakan adalah cross sectional.

Adapun populasi dan sampel dalam penelitian adalah kader kesehatan TB aktif di Kabupaten Kuningan dengan jumlah sebanyak 65. Teknik dan pengambilan sampel dalam penelitian ini bersifat sampel total (total sampling). Instrumen yang digunakan pada saat penelitian yaitu kuesioner sebagai alat wawancara peneliti kepada responden dan lembar kinerja sebagai alat ukur kinerja kader.

Analisis data yang akan digunakan adalah analisis univariat, bivariat. Analisis bivariat yang digunakan adalah uji chisquare dan rank spearman yang dapat mengetahui ada hubungan antara variabel kategorik dengan variabel kategorik 
JOURNAL OF PUBLIC HEALTH INOVATION

VOL. 02. NO. 01, DESEMBER 2021

DOI: $10.34305 /$ jphi.v2i1.345
Ciptaan disebarluaskan di bawah

Lisensi Creative Commons Atribusi-

NonKomersial-BerbagiSerupa 4.0 Internasional.

\section{Hasil}

\section{Analisis Univariat}

\section{Tabel 1 Gambaran Distribusi Kader Kesehatan Tuberkulosis di Kabupaten Kuningan}

Tahun 2020

\begin{tabular}{lcc}
\hline Karakteristik Responden & Frekuensi $(f)$ & Persentase (\%) \\
\hline Umur & 34 & 52.3 \\
Dewasa (26-45 tahun.) & 31 & 47.7 \\
Lansia ( 46 tahun.) & 17 & 26 \\
\hline Pendidikan & 46 & 71 \\
Dasar (SD/MI dan SMP/ MTs) & 2 & 3 \\
Menengah (SMA/SMK) & & \\
Tinggi (Perguruan Tinggi) & 45 & 69 \\
\hline Status Pekerjaan & 20 & 31 \\
Tidak Bekerja (IRT) & & \\
Bekerja & 41 & 63 \\
\hline Masa Kerja & 24 & 37 \\
Baru (<3 tahun) & & \\
Lama ( $\geq 3$ tahun) & 0 & 0 \\
\hline Motivasi & 35 & 54 \\
Rendah & 30 & 46 \\
Cukup & & \\
Tinggi & 27 & 41.5 \\
\hline Sikap & 38 & 58.5 \\
Negatif & Frekuensi $(f)$ & 64.6 \\
Positif & 42 & $\mathbf{1 0 0}$ \\
\hline Karakteristik Responden & 23 & \\
\hline Kinerja & $\mathbf{6 5}$ & Persentase (\%) \\
Kurang baik & & \\
Baik & & \\
Jumlah & & \\
\hline
\end{tabular}

Berdasarkan tabel 1 dapat dilihat bahwa dari 65 kader, sebagian besar kader memiliki kinerja yang kurang baik yaitu sebanyak $64.6 \%$ sebagian besar kader berada di kelompok dewasa (26-45 tahun.) yaitu sebanyak 52.3\%. Sedangkan kader yang berada di kelompok umur lansia ( $>45$ tahun) yaitu sebanyak 47.7\%. Sebagian besar kader berpendidikan menengah (Lulusan SMA/ SMK) yaitu sebanyak 71\%. Kemudian sebagian besar berstatus tidak bekerja (mengurus rumah tangga) yaitu sebanyak 69\%. Serta sebagian besar kader memiliki masa kerja yang baru ( $<3$ tahun) 
JOURNAL OF PUBLIC HEALTH INOVATION

VOL. 02. NO. 01, DESEMBER 2021

DOI: $10.34305 /$ jphi.v2i1.345
Ciptaan disebarluaskan di bawah

Lisensi Creative Commons Atribusi-

NonKomersial-BerbagiSerupa 4.0 Internasional yaitu sebanyak 63\%. Kemudian tidak ada kader yang memiliki motivasi Rendah.

Semua kader memiliki motivasi dengan kategori cukup (54\%) dan sebagian besar kader memiliki sikap yang positif (baik) dalam menjalankan tugasnya saat pandemi COVID-19 yaitu sebanyak 58.5\%.

\section{Analisis Bivariat}

Tabel 2 Analisis Umur, Tingkat Pendidikan, Masa Kerja dan Motivasi dengan Kinerja Kader Kesehatan TB di Kabupaten Kuningan

\begin{tabular}{|c|c|c|c|c|c|c|c|c|}
\hline \multirow[t]{3}{*}{ Umur } & \multicolumn{4}{|c|}{ Kinerja } & \multirow{2}{*}{\multicolumn{2}{|c|}{ Total }} & \multirow[t]{3}{*}{ P-Value } & \multirow[t]{3}{*}{$r$} \\
\hline & \multicolumn{2}{|c|}{ Kurang Baik } & \multicolumn{2}{|c|}{ Baik } & & & & \\
\hline & $\mathbf{n}$ & $\%$ & $\mathbf{n}$ & $\%$ & $\mathbf{N}$ & $\%$ & & \\
\hline Dewasa (26-45 tahun.) & 24 & 70.6 & 10 & 29.4 & 34 & 100 & 0.003 & 0.362 \\
\hline Lansia ( $>46$ tahun.) & 18 & 58 & 13 & 42 & 31 & 100 & & \\
\hline Jumlah & 42 & 64.6 & 23 & 35.4 & 65 & 100 & & \\
\hline \multicolumn{9}{|l|}{ Tingkat Pendidikan } \\
\hline Dasar & 10 & 59 & 7 & 41 & 17 & 100 & 0.098 & 0.207 \\
\hline Menengah & 32 & 70 & 14 & 30 & 46 & 100 & & \\
\hline Tinggi & 0 & 0 & 2 & 100 & 2 & 100 & & \\
\hline Jumlah & 42 & 64.6 & 23 & 34 & 50 & 100 & & \\
\hline \multicolumn{9}{|l|}{ Masa Kerja } \\
\hline Baru ( $<3$ tahun) & 34 & 83 & 7 & 17 & 24 & 100 & 0.001 & 0.588 \\
\hline Lama ( $\geq 3$ tahun) & 8 & 33 & 16 & 67 & 41 & 100 & & \\
\hline Jumlah & 42 & 64.6 & 23 & 34 & 50 & 100 & & \\
\hline \multirow[t]{3}{*}{ Motivasi } & \multicolumn{4}{|c|}{ Kinerja } & \multirow{2}{*}{\multicolumn{2}{|c|}{ Total }} & P-Value & $r$ \\
\hline & \multicolumn{2}{|c|}{ Kurang Baik } & \multicolumn{2}{|c|}{ Baik } & & & & \\
\hline & $\mathbf{n}$ & $\%$ & $\mathrm{n}$ & $\%$ & $\mathbf{N}$ & $\%$ & & \\
\hline Cukup & 28 & 80 & 7 & 20 & 35 & 100 & 0.010 & 0.316 \\
\hline Tinggi & 14 & 46.7 & 16 & 53.3 & 30 & 100 & & \\
\hline Jumlah & 42 & 64.6 & 23 & 34 & 50 & 100 & & \\
\hline
\end{tabular}

Berdasarkan uji hipotesis (spearman's rho) diperoleh $r$ hitung (0.362) $>r$ tabel (0.244) maka dapat disimpulkan bahwa terdapat hubungan yang signifikan antara umur dengan kinerja kader kesehatan TB di Kabupaten Kuningan tahun 2020 $(\mathrm{P}=0.003)$. Nilai $r=0.362$ menandakan hubungan yang lemah dengan arah positif (searah), artinya semakin banyak kader yang berada pada kelompok umur lansia maka semakin banyak pula kader yang memiliki kinerja baik. Berdasarkan uji hipotesis (spearman's rho) diperoleh $r$ hitung $(0.207)<r$ tabel $(0.244)$ maka dapat 
JOURNAL OF PUBLIC HEALTH INOVATION

VOL. 02. NO. 01, DESEMBER 2021

DOI: $10.34305 /$ jphi.v2i1.345
Ciptaan disebarluaskan di bawah

Lisensi Creative Commons Atribusi-

NonKomersial-BerbagiSerupa 4.0 Internasional.

disimpulkan bahwa tidak terdapat TB di Kabupaten Kuningan tahun 2020 hubungan yang signifikan antara tingkat $(P=0.098)$.

pendidikan dengan kinerja kader kesehatan

Tabel 3 Hubungan Status Pekerjaan dengan Kinerja Kader Kesehatan TB di Kabupaten Kuningan Pada Saat Pandemi COVID-19 Tahun 2020

\begin{tabular}{|c|c|c|c|c|c|c|c|}
\hline \multirow{3}{*}{ Status Pekerjaan } & \multicolumn{4}{|c|}{ Kinerja } & \multirow{2}{*}{\multicolumn{2}{|c|}{ Total }} & \multirow{3}{*}{ P-Value } \\
\hline & \multicolumn{2}{|c|}{ Kurang Baik } & \multicolumn{2}{|c|}{ Baik } & & & \\
\hline & $\mathbf{n}$ & $\%$ & $\mathrm{n}$ & $\%$ & $\mathbf{N}$ & $\%$ & \\
\hline Bekerja & 15 & 75 & 5 & 45,8 & 35 & 100 & \\
\hline Tidak Bekerja & 27 & 60 & 18 & 6,7 & 15 & 100 & 0.375 \\
\hline Jumlah & 42 & 64.6 & 23 & 34 & 50 & 100 & \\
\hline
\end{tabular}

Berdasarkan uji hipotesis dapat kinerja kader kesehatan TB di Kabupaten dilihat bahwa tidak terdapat hubungan yang Kuningan pada saat pandemi COVID-19 signifikan antara status pekerjaan dengan tahun $2020(\mathrm{P}=0.375)$.

Tabel 4 Hubungan Masa Kerja dengan Kinerja Kader Kesehatan TB di Kabupaten Kuningan

\begin{tabular}{|c|c|c|c|c|c|c|c|c|}
\hline \multirow{3}{*}{ Masa Kerja } & \multicolumn{4}{|c|}{ Kinerja } & \multirow{2}{*}{\multicolumn{2}{|c|}{ Total }} & \multirow{3}{*}{ P-Value } & \multirow{3}{*}{$\boldsymbol{r}$} \\
\hline & \multicolumn{2}{|c|}{ Kurang Baik } & \multicolumn{2}{|c|}{ Baik } & & & & \\
\hline & $\mathbf{n}$ & $\%$ & $\mathbf{n}$ & $\%$ & $\mathbf{N}$ & $\%$ & & \\
\hline Baru ( $<3$ tahun) & 34 & 83 & 7 & 17 & 24 & 100 & & \\
\hline Lama ( $\geq 3$ tahun) & 8 & 33 & 16 & 67 & 41 & 100 & 0.001 & 0.588 \\
\hline Jumlah & 42 & 64.6 & 23 & 34 & 50 & 100 & & \\
\hline
\end{tabular}

Berdasarkan uji hipotesis (spearman's rho) diperoleh $r$ hitung (0.588) $>r$ tabel (0.244) maka dapat disimpulkan bahwa terdapat hubungan yang signifikan antara masa kerja dengan kinerja kader kesehatan TB di Kabupaten Kuningan tahun $2020 \quad(P=0.001)$. Nilai $r=0.588$ menandakan hubungan yang kuat dengan arah positif (searah), artinya semakin banyak kader yang memiliki masa kerja lama ( $\geq 3$ tahun) maka semakin banyak pula kader yang memiliki kinerja baik. 
JOURNAL OF PUBLIC HEALTH INOVATION

VOL. 02. NO. 01, DESEMBER 2021

DOI: $10.34305 /$ jphi.v2i1.345
Ciptaan disebarluaskan di bawah

Lisensi Creative Commons Atribusi-

NonKomersial-BerbagiSerupa 4.0

Tabel 5 Hubungan Motivasi Kader dengan Kinerja Kader Kesehatan TB di Kabupaten Kuningan

\begin{tabular}{|c|c|c|c|c|c|c|c|c|}
\hline \multirow{3}{*}{ Motivasi } & \multicolumn{4}{|c|}{ Kinerja } & \multirow{2}{*}{\multicolumn{2}{|c|}{ Total }} & \multirow{3}{*}{ P-Value } & \multirow{3}{*}{$r$} \\
\hline & \multicolumn{2}{|c|}{ Kurang Baik } & \multicolumn{2}{|c|}{ Baik } & & & & \\
\hline & $\mathrm{n}$ & $\%$ & $\mathrm{n}$ & $\%$ & $\mathbf{N}$ & $\%$ & & \\
\hline Cukup & 28 & 80 & 7 & 20 & 35 & 100 & & \\
\hline Tinggi & 14 & 46.7 & 16 & 53.3 & 30 & 100 & 0.010 & 0.316 \\
\hline Jumlah & 42 & 64.6 & 23 & 34 & 50 & 100 & & \\
\hline
\end{tabular}

(Sumber: Olah Data 2021)

Berdasarkan uji hipotesis (spearman's rho) diperoleh r hitung (0.316) $>\mathrm{r}$ tabel (0.244) maka dapat disimpulkan bahwa terdapat hubungan yang signifikan antara motivasi dengan kinerja kader kesehatan TB di Kabupaten Kuningan tahun $2020 \quad(\mathrm{P}=0.010)$. Nilai $\quad \mathrm{r}=0.316$ menandakan hubungan yang lemah dengan arah positif (searah), artinya semakin banyak kader yang memiliki motivasi tinggi maka semakin banyak pula kader yang memiliki kinerja baik.

Tabel 6 Hubungan Sikap Kader dengan Kinerja Kader Kesehatan TB di Kabupaten Kuningan Pada Saat Pandemi COVID-19 Tahun 2020

\begin{tabular}{|c|c|c|c|c|c|c|c|c|}
\hline \multirow{3}{*}{ Sikap } & \multicolumn{4}{|c|}{ Kinerja } & \multirow{2}{*}{\multicolumn{2}{|c|}{ Total }} & \multirow{3}{*}{ P-Value } & \multirow{3}{*}{$\begin{array}{c}\text { PR } \\
\text { (CI 95\%) }\end{array}$} \\
\hline & \multicolumn{2}{|c|}{ Kurang Baik } & \multicolumn{2}{|c|}{ Baik } & & & & \\
\hline & $\mathbf{N}$ & $\%$ & $\mathbf{N}$ & $\%$ & $\mathbf{N}$ & $\%$ & & \\
\hline Negatif & 24 & 88.9 & 3 & 11.1 & 27 & 100 & \multirow{3}{*}{0.001} & \multirow{3}{*}{$\begin{array}{c}8.889 \\
(2.284- \\
34.587)\end{array}$} \\
\hline Positif & 18 & 47.4 & 20 & 52.6 & 38 & 100 & & \\
\hline Jumlah & 42 & 64.6 & 23 & 35.4 & 65 & 100 & & \\
\hline
\end{tabular}

Berdasarkan uji hipotesis dapat disimpulkan bahwa terdapat hubungan yang signifikan antara sikap kader dengan kinerja kader kesehatan TB di Kabupaten Kuningan tahun $2020(\mathrm{P}=0.001)$. Kemudian kader yang bersikap negatif memiliki kemungkinan hampir 9 kali lebih besar berkinerja kurang baik dibandingkan dengan kader yang bersikap positif dengan nilai $P R=8.889(2.284-34.587)$. 
JOURNAL OF PUBLIC HEALTH INOVATION

VOL. 02. NO. 01, DESEMBER 2021

DOI: $10.34305 /$ iphi.v2i1.345

\section{Pembahasan}

Hubungan Umur dengan Kinerja Kader Kesehatan TB di Kabupaten Kuningan pada tahun 2020

Berdasarkan hasil uji hipotesis dapat disimpulkan bahwa tidak ada hubunganyang signifikan antara umur dengan kinerja kader kesehatan TB (nilai $\rho$ $=0.321)$.

Hasil ini sejalan dengan penelitian Iswari \& Porusia (2018) yang mengemukakan bahwa "Tidak ada terdapat hubungan yang signifikan antara umur kader terhadap penemuan suspek TB (nilai $\rho=0,435)$ ". Kemudian diperkuat dengan penelitian Nisa \& Dyah (2017) bahwa "Nilai P value usia kader sebesar 0,7 (Pvalue $>0,005)$, artinya tidak ada hubungan yang signifikan antara usia kader kesehatan dengan praktik penemuan kasus Tuberkulosis".

Pada penelitian ini umur tidak berhubungan dengan kinerja karena tidak semua kader berumur muda saat memulai bertugas menjadi kader kesehatan TB. Karena pada saat pengkaderan, seseorang yang ingin menjadi kader tidak dikenakan batasan umur. Sehingga dimungkinkan ada kader yang sudah ber kategori umur lansia
Ciptaan disebarluaskan di bawah Lisensi Creative Commons AtribusiNonKomersial-BerbagiSerupa 4.0

baru menjadi kader dan berkinerja kurang baik.

Seiring bertambahnya umur seseorang akan meningkatkan kemampuan dalam mengambil keputusan, berpikir rasional, mengendalikan emosi, dan toleransi terhadap pandangan orang lain. Akan tetapi dalam hal pekerjaan, seseorang yang berumur lebih tua akan menurun tingkat produktivitasnya dibandingkan dengan yang berumur lebih muda (Iswari \& Porusia, 2018).

Hubungan Status Pendidikan dengan Kinerja Kader Kesehatan TB di Kabupaten Kuningan pada tahun 2020

Berdasarkan hasil uji hipotesis dapat disimpulkan bahwa tidak ada hubungan yang signifikan antara umur dengan kinerja kader kesehatan TB (nilai $\rho=0.523$ ). Hal ini karena distribusi variabel pendidikan kader yang berkategori menengah jumlahnya $71 \%$, berbeda sangat jauh dengan kategori tinggi dan rendah.

Tingkat pendidikan tidak berhubungan dengan kinerja karena dalam menjalankan tugasnya, kader lebih menggunakan ilmu pengetahuan yang didapat dari pendidikan non formal. Pendidikan non formal yang diberikan kepada kader kesehatan di Kabupaten 
JOURNAL OF PUBLIC HEALTH INOVATION

VOL. 02. NO. 01, DESEMBER 2021

DOI: $10.34305 /$ jphi.v2i1.345
Ciptaan disebarluaskan di bawah

Lisensi Creative Commons Atribusi-

NonKomersial-BerbagiSerupa 4.0
Kuningan antara lain workshop dan pelatihan mengenai program eliminasi TB.

Dengan latar belakang kader yang berpendidikan menengah (lulus SMA/MA/SMK/SMA/Sederajat) semua kader memiliki pemahaman yang sama mengenai program ini.

Hal ini sejalan dengan penelitian Ratnasari (2020) yang menyebutkan bahwa "Nilai $\rho=0,098$ yang artinya tidak terdapat hubungan antara tingkat pendidikan dengan kinerja kader dalam penemuan kasus Tuberkulosis".

Kemudian penelitian Sukandar, Faiqoh \& Effendi (2019) mengemukakan bahwa "Tidak ditemukannya hubungan pada karakteristik pendidikan terakhir $(\mathrm{P}$ $=0,803)$. Perbedaan yang signifikan antara kedua variabel hanya ditemukan pada karakteristik pengalaman mengikuti pelatihan kader dengan nilai $\mathrm{P}<0,05$ $(0,019)$ ". Hal ini mengartikan bahwa pendidikan formal yang lebih tinggi cenderung akan mempunyai sikap dan pengetahuan yang lebih baik, akan tetapi pendidikan non formal juga dapat mempengaruhi kinerja kader.

Semakin tinggi tingkat pendidikan seseorang, maka akan semakin berkembang pula pola pikir seseorang, dan akan berujung kepada kesadaran akan kesehatan diri dan keluarga. Melalui proses pendidikan, seseorang akan mempelajari berbagai ilmu sehingga akan menjadi tahu tentang banyak hal. Masyarakat yang memiliki tingkat pendidikan tinggi, akan mudah dalam menyerap berbagai informasi dan juga mempengaruhi tingkat pendapatannya (Banna et al., 2020).

Hubungan Status Pekerjaan dengan Kinerja Kader Kesehatan TB di Kabupaten Kuningan Pada Saat Pandemi COVID-19 Tahun 2020

Berdasarkan uji hipotesis menyatakan bahwa tidak terdapat hubungan yang signifikan antara status pekerjaan dengan kinerja kader kesehatan TB di Kabupaten Kuningan tahun 2020 (nilai $\mathrm{P}=$ 0.375). Kader yang tidak bekerja mempunyai waktu luang yang lebih banyak untuk melakukan kegiatan program eliminasi TB seperti investigasi kontak (IK) dan penyuluhan. Karena itu seharusnya kader lebih giat melakukan IK dan penyuluhan TB.

Fakta di lapangan menemukan bahwa kader kesehatan yang diteliti berasal dari ibu-ibu yang tergabung dalam kelompok PKK, majelis taklim dan kader Posyandu. Sehingga kader kesehatan tidak hanya melakukan IK dan penyuluhan saja, 
JOURNAL OF PUBLIC HEALTH INOVATION

VOL. 02. NO. 01, DESEMBER 2021

DOI: $10.34305 /$ jphi.v2i1.345

melainkan melakukan kegiatan lain seperti, melaksanakan program PKK mengikuti pengajian rutin dan melaksanakan kegiatan Posyandu walaupun tidak dilakukan setiap hari. Hal ini menjadi salah satu kekurangan penelitian yang melihat status pekerjaan kader hanya melihat status pekerjaan pada KTPnya saja. Sehingga kader yang memiliki kegiatan organisasi dan kader lain dianggap tidak bekerja selama status pekerjaan di KTPnya Mengurus Rumah Tangga.

Hasil penelitian ini sejalan dengan penelitian Nisa \& Dyah (2017) "Nilai P value untuk pekerjaan kader sebesar 0,34 (P value $>0,005)$ artinya tidak ada hubungan yang signifikan antara pekerjaan kader kesehatan dengan praktik penemuan tersangka kasus tuberkulosis paru di Wilayah Kerja Puskesmas Tlogosari Kulon Kota Semarang”. Kemudian penelitian Ratnasari (2020) yang mengemukakan bahwa tidak ada hubungan signifikan antara faktor sosio demografis yang meliputi umur, pendidikan dan pekerjaan terhadap kinerja kader dalam pencegahan kejadian TB.

Hubungan Masa Kerja dengan Kinerja Kader Kesehatan TB di Kabupaten Kuningan pada tahun 2020
Ciptaan disebarluaskan di bawah Lisensi Creative Commons AtribusiNonKomersial-BerbagiSerupa 4.0 Internasional

Dari uji hipotesis diperoleh bahwa terdapat hubungan yang signifikan antara masa kerja dengan kinerja kader kesehatan TB (nilai $\rho=0.016$ ). Kemudian nilai signifikansi (2-tailed) adalah 0.901 yang menandakan hubungannya sangat kuat antara status pendidikan dengan kinerja kader kesehatan TB.

Hal ini sesuai teori Sumartini (2014) yang mengemukakan bahwa lama kerja berhubungan signifikan dengan peran kader kesehatan TB dalam penemuan kasus TB. Lama masa kerja sangat mempengaruhi kinerja yang ditunjukkan oleh kader, karena masa kerja adalah jangka waktu bekerja pada suatu usaha/kantor dimana masa kerja merupakan indikator dalam menentukan produktivitas, karena semakin berpengalaman dan terampil menyelesaikan tugas yang dipercayakan kepadanya.

Hasil ini didukung dengan penelitian Widjanarko, Prabamurti \& Widayat (2018) bahwa "Hasil menunjukkan bahwa ada hubungan yang signifikan antara masa kerja kader dengan praktik penemuan suspek TB paru pada tingkat kesalahan (5 \%) dengan nilai $\rho=0,004$.”. Kemudian penelitian Sukandar, Faiqoh \& Effendi (2019) yang mengemukakan bahwa "Hasil Uji chi square menunjukkan adanya hubungan lama menjadi kader dengan 
JOURNAL OF PUBLIC HEALTH INOVATION

VOL. 02. NO. 01, DESEMBER 2021

DOI: $10.34305 /$ jphi.v2i1.345

kinerja kader kesehatan $(P$-value $=0,019)$ di Kecamatan Soreang”.

Pada saat pengkaderan, calon kader tidak ditentukan berdasarkan batasan umur, maka kader yang memiliki masa kerja lama ( $\geq 3$ tahun) belum tentu berada pada kelompok umur yang lebih tua (lansia). Hal ini terjadi karena pengkaderan dilakukan secara berkala pada tahun 2018-2019 sehingga waktu masuk menjadi kader yang berbeda-beda. Kemudian berdasarkan data yang peneliti dapat, kader yang memiliki masa kerja lama sebelumnya sudah pernah menjadi kader dibawah naungan Lembaga Aisyah TB Comunity pada program yang sama yaitu program eliminasi TB. Maka dari itu kader tersebut sudah memahami cara kerja dari kegiatan di program ini.

Kader yang belum memiliki pengalaman belum terbiasa dan paham dengan kebijakan petugas puskesmas dalam pelaksanaan di lapangan. Sehingga hanya menjalankan tugas dari koordinator program. Dari temuan dilapangan, kader yang sudah lama memiliki pemahaman program yang lebih dibandingkan dengan kader baru.

Hubungan Motivasi Kader dengan Kinerja Kader Kesehatan TB di Kabupaten Kuningan pada tahun 2020
Ciptaan disebarluaskan di bawah Lisensi Creative Commons AtribusiNonKomersial-BerbagiSerupa 4.0 Internasional

Hasil uji hipotesis yang terdapat pada tabel 4 dapat disimpulkan bahwa ada hubungan yang signifikan antara motivasi dengan kinerja kader kesehatan TB (nilai $\rho$ $=0.131)$. Kemudian nilai signifikansi (2tailed) adalah 0.136 hal ini menandakan hubungan yang sangat lemah antara motivasi dengan kinerja kader kesehatan TB. Sehingga diperlukan dorongan motivasi yang lebih untuk menjadikan kader berkinerja baik.

Hasil penelitian ini sesuai dengan teori pada hasil penelitian Profita (2018) yang menyatakan bahwa "Hasil penelitian menunjukkan terdapat hubungan antara motivasi dengan keaktifan kader". Kemudian didukung oleh hasil penelitian Afifa (2019) yang menyatakan bahwa "Ada hubungan yang signifikan antara motivasi dengan kinerja kader kesehatan (nilai $\rho=$ 0.002). Semakin tinggi tingkat motivasi yang dimiliki kader maka kinerjanya akan semakin baik". Motivasi yang tinggi dapat meningkatkan keaktifan kader lebih baik yang juga berpengaruh terhadap kualitas kinerjanya dibandingkan dengan kader yang memiliki motivasi cukup-rendah.

Hal yang sama juga dikemukakan oleh Wijaya (2013) bahwa "terdapat hubungan yang secara statistik signifikan antara motivasi dengan keaktifan kader 
JOURNAL OF PUBLIC HEALTH INOVATION

VOL. 02. NO. 01, DESEMBER 2021

DOI: $10.34305 /$ iphi.v2i1.345

kesehatan, dimana motivasi tinggi memiliki kemungkinan untuk aktif dalam pengendalian kasus tuberkulosis 15 kali lebih besar dari pada motivasi rendah". Hal yang sama dikemukakan oleh Wardani, Asrinawaty \& Norfai (2020) bahwa "Hasil uji statistik Chi-Square didapatkan P-value $(0,04) \leq \alpha(0,05)$, yang berarti terdapat hubungan yang bermakna antara motivasi kader dengan penemuan suspek TB paru di Puskesmas Karang Mekar Tahun 2019”.

Hal ini dikarenakan motivasi adalah salah satu faktor pendorong bagi seseorang untuk melakukan tindakan. Semakin kuat dorongan dalam diri yang dimiliki maka semakin mudah seseorang untuk bergerak guna mencapai suatu tujuan. (Wardani et al., 2020). Motivasi pada seseorang akan berbeda berdasarkan umurnya. Semakin tua maka motivasinya akan semakin bertambah karena ada beberapa indikator lain yang menjadi tujuannya. Dalam upaya meningkatkan motivasi kader perlunya pemberian insentif (reward) sebagai tujuan untuk memenuhi kebutuhan fisiologisnya. Selain kebutuhan fisiologis, pada kader yang lebih tua motivasi terbangun dari kesadaran kader untuk membantu masyarakat mengidentifikasi penemuan suspek sebagai bentuk pengakuan diri
Ciptaan disebarluaskan di bawah Lisensi Creative Commons AtribusiNonKomersial-BerbagiSerupa 4.0 Internasional.

(aktualisasi diri) (Jannah et al., 2019; Prihartanta, 2015)

Hubungan Sikap Kader dengan Kinerja Kader Kesehatan TB di Kabupaten Kuningan pada tahun 2020

Berdasarkan uji hipotesis dapat disimpulkan bahwa terdapat hubungan yang signifikan antara sikap kader terhadap pekerjaannya dengan kinerja kader kesehatan TB di Kabupaten Kuningan saat pandemi COVID-19 tahun 2020. Kemudian kader yang bersikap negatif memiliki kemungkinan hampir 9 kali lebih besar berkinerja kurang baik dibandingkan dengan kader yang bersikap positif dan sebaliknya, dengan Nilai PR $=8.889(2.284$ - 34.587).

Hal ini sejalan dengan penelitian Shalsabila, Cahyo \& Indraswa (2018) mengemukakan bahwa "ada hubungan antara sikap responden dengan pencapaian target CDR $(P=0.005)$. Semakin buruk (negatif) sikap kader terkait TB maka semakin buruk pula pencapaian target CDR dalam penemuan kasus TB”. Selanjutnya pada penelitian Hoko, Kurniawati \& Maryanti (2019) yang menunjukkan bahwa "Semakin kurang baik (negatif) sikap kader tentang tugas kader dalam penemuan kasus TB, semakin menurun pula tindakan kader 
JOURNAL OF PUBLIC HEALTH INOVATION

VOL. 02. NO. 01, DESEMBER 2021

DOI: $10.34305 /$ jphi.v2i1.345

dalam penemuan kasus TB”. Kemudian diperkuat oleh penelitian (Banna, Pademme\& Simon (2020) yang menyebutkan bahwa "Ada hubungan antara sikap kader dengan praktik penemuan suspek TB paru $(\mathrm{P}$ value $=0.000)$ ".

Sikap pada penelitian ini dilihat dari faktor internal (perspektif) dan eksternal (situasi dan kondisi lingkungan) seseorang. Pada situasi pandemi kader kesehatan TB banyak kader yang melakukan penyesuaian dalam melakukan kegiatan program (IK dan penyuluhan). Pada umumnya semua kader memiliki sikap yang positif. Akan tetapi dengan adanya faktor eksternal terjadi sedikit perubahan pada sikap kader yang positif menjadi negatif.

Faktor eksternal (situasi dan kondisi lingkungan) saat pandemi berkaitan erat dengan pelaksanaan kegiatan program sehingga mempengaruhi kinerja kader. Situasi lingkungan yang dimaksud diantaranya adalah kebijakan pemerintah dan penerimaan informasi yang keliru kepada kader yang masih labil mengakibatkan perubahan sikap kader tersebut untuk menjalankan program sehingga sikapnya menjadi negatif.

\section{Kesimpulan}

Ciptaan disebarluaskan di bawah Lisensi Creative Commons AtribusiNonKomersial-BerbagiSerupa 4.0 Internasional.

Dari 65 responden, $64.6 \%$ responden memiliki kinerja yang kurang baik. sebanyak 52.3\% kader berada di kelompok umur dewasa (26-45 tahun), $70.8 \%$ kader berpendidikan menengah (Lulusan $\quad$ SMA/SMK), $\quad 69.2 \% \quad$ kader berstatus tidak bekerja (mengurus rumah tangga), 63.1\% kader memiliki masa kerja yang baru $(<3$ tahun), 52.3\% kader memiliki motivasi yang cukup dan 58.5\% kader memiliki sikap yang positif. Analisis bivariat dengan uji chi-square antara status pekerjaan, dan sikap dengan kinerja kader nilai $\mathrm{P}$ berturut-turut : $0.375,0.001$. Kemudian uji rank spearman antara umur, pendidikan, masa kerja dan motivasi dengan kinerja kader nilai $\rho$ berturut-turut : $0.321,0.523,0.016,0.182$.

\section{Saran}

Dalam upaya pemeliharaan kader yang berkelanjutan, maka Dinas Kesehatan perlu adanya penyegaran kembali kader kesehatan agar dapat menyesuaikan dengan situasi dan kondisi lingkungan serta memberikan motivasi semangat menjadi kader. Kemudian Dinas Kesehatan juga agar lebih giat memberikan berbagai pendidikan non formal serta peningkatan motivasi kepada kader agar dapat meningkatkan penemuan terduga TB 
JOURNAL OF PUBLIC HEALTH INOVATION

VOL. 02. NO. 01, DESEMBER 2021

DOI: $10.34305 /$ iphi.v2i1.345

melalui investigasi kotak (IK) dan

Penyuluhan kepada masyarakat mengenai

TB. Sehingga dimasa yang akan datang

kader tersebut sudah terampil dan memiliki

kinerja yang baik.

\section{Daftar Pustaka}

A'maliyah, A., \& Wahyono, B. (2021). Analisis Kinerja Petugas Pelaksana Program Penanggulangan Tuberkulosis Paru Dalam Penemuan Kasus Baru Di Puskesmas Tegal Timur Kota Tegal. Indonesian Journal Of Public Health And Nutrition, I(1), $1-12$.

Https://Doi.Org/Https://Doi.Org/Https: //Doi.Org

Afifa, I. (2019). Kinerja Kader Dalam Pencegahan Stunting: Peran Lama Kerja Sebagai Kader , Pengetahuan Dan Motivasi The Cadre Performa In Stunting Prevention : Rule Of Working Duration As Cadre, Knowledge, And Motivation. Jurnal Kedokteran Brawijaya, 30(4), 336-341.

Banna, T., Pademme, D., \& Simon, M. (2020). Hubungan Antara Pengetahuan Dan Sikap Kader Kesehatan Dengan Praktik Penemuan Suspek Penderita Tuberkulosis Paru. Jurnal Kesehatan, 11(2), 118-123. Http://Jurnal.Stikescirebon.Ac.Id/Inde x.Php/Kesehatan/Article/View/225

Coenraad, D. P., Nurdiansyah, H., \& Adinata, U. W. S. (2020). Pengaruh Motivasi Intrinsik Dan Ekstrinsik Terhadap Kinerja Kader Posyandu. Makro: Jurnal Manajemen Dan Kewirausahaan, 22(1), 46-59. Https://Doi.Org/Https://Doi.Org/10.36
Ciptaan disebarluaskan di bawah

Lisensi Creative Commons Atribusi-

NonKomersial-BerbagiSerupa 4.0

Internasional.

467/Makro.2020.05.01.04

Dinas Kesehatan Jawa Barat. (2020). Profil Kesehatan Jawa Barat Tahun 2019. Dinas Kesehatan Jawa Barat. Www.Diskes.Jabarprov.Go.Id

Dinas Kesehatan Kabupaten Kuningan. (2020). Profil Kesehatan Kuningan. Dinas Kesehatan Kabupaten Kuningan Jawa Barat.

Dirjen Pencegahan Dan Pengendalian Penyakit. (2020). Peta Jalan Eliminasi Tuberkulosis. TBC Indonesia, 1(2016), $1-2$.

Https://Tbindonesia.Or.Id/Profil/PetaJalan-Eliminasi/

Hanum, F., \& Yanuarita, H. A. (2020). Pelayanan Kesehatan Dalam Program Community $\mathrm{Tb}$ Care Aisyiyah Kabupaten Kediri. Jurnal Mediasosian : Jurnal Ilmu Sosial Dan Administrasi Negara, 4(2), 193-204. Https://Doi.Org/Https://Doi.Org/10.30 737/Mediasosian.V4i2.1206

Hoko, S. S., Kurniawati, N. D., \& Maryanti, H. (2019). Hubungan Pengetahuan Dan Sikap Kader Posyandu Tentang Tugas Pengembangan Kader Terhadap Tindakan Penemuan Kasus Tb Paru Di Puskesmas Lite. Indonesian Journal Of Community Health Nursing, 2(2), $50-56$.

$\mathrm{Https}: / / \mathrm{E}-$ Journal.Unair.Ac.Id/IJCHN/Article/Vi ew/11918/6853

Iswari, A. P., \& Porusia, M. (2018). Cadre Performance Factor Of Community Tb-Hiv Care 'Aisyiyah On Finding Tb Suspect In Surakarta. The 8th University Research Colloquium 2018, 24-33. 
JOURNAL OF PUBLIC HEALTH INOVATION

VOL. 02. NO. 01, DESEMBER 2021

DOI: $10.34305 /$ iphi.v2i1.345

Jannah, I., Ridha, A., \& Rochmawati, R. (2019). Hubungan Pelatihan, Imbalan, Supervisi, Dan Motivasi Dengan Kinerja Kader Jumantik Di Kecamatan Pontianak Timur Kota Pontianak. JUMANTIK: Jurnal Mahasiswa Dan Peneliti Kesehatan, 6(2), 42-49.

Nisa, S. M., \& Dyah, Y. (2017). Hubungan Antara Karakteristik Kader Kesehatan Dengan Praktik Penemuan Tersangka Kasus Tuberkulosis Paru. Journal Of Health Education (JHE ), 2(1), 93100.

Https://Doi.Org/Https://Doi.Org/10.15 294/Jhe. V2i1.19117

Prihartanta, W. (2015). Teori-Teori Motivasi. Jurnal Adabiya, Tahun 2015, 1(83), 1-11. Https://Www.Academia.Com

Profita, A. C. (2018). Beberapa Faktor Yang Berhubungan Dengan Keaktifan Kader Posyandu Di Desa Pengadegan Kabupaten Banyumas. Jurnal Administrasi Kesehatan Indonesia, 6(2), 68 Https://Doi.Org/Https://Doi.Org/10.20 473/Jaki.V6i2. 2018.68-74

Ratnasari, N. Y. (2020). Peran Kader Kesehatan Dalam Pencegahan Kejadian Tuberkulosis Di Wonogiri. Jurnal Penelitian Kesehatan Suara Forikes, 11(1), 97-101.

Rinayati, Erawati, A. D., \& Wahyuning, S. (2020). Gambaran Tingkat Pengetahuan Dan Kinerja Kader Kesehatan. Jurnal Ilmiah Permas: Jurnal Ilmiah STIKES Kendal, 10(3), 359-364.

Shalsabila, M., Cahyo, K., \& Indraswa, R.
Ciptaan disebarluaskan di bawah

Lisensi Creative Commons Atribusi-

NonKomersial-BerbagiSerupa 4.0

Internasional.

(2018). Beberapa Faktor Yang Mempengaruhi Pencapaian Target CDR Oleh Kader TB 'Aisyiyah Dalam Penemuan Kasus TB Di Kota Semarang. Jurnal Kesehatan Masyarakat (E-Journal), 6(4), 582586.

Http://Ejournal3.Undip.Ac.Id/Index.Ph $\mathrm{p} / \mathrm{Jkm}$

Sukandar, H., Faiqoh, R., \& Effendi, J. S. (2019). Hubungan Karakteristik Terhadap Tingkat Aktivitas Kader Posyandu Kecamatan Soreang Kabupaten Bandung. Jurnal Sistem Kesehatan, 4(3), 102-109.

Sumartini, N. P. (2014). Penguatan Peran Kader Kesehatan Dalam Penemuan Kasus Tuberkulosis (TB) BTA Positif Melalui Edukasi Dengan Pendekatan Theory Of Planned Behaviour (TPB). Jurnal Kesehatan Prima, 8(1), 12461263.

Wardani, A. K., Asrinawaty, \& N. (2020). Cadres' Knowledge, Attitude And Motivation As The Determinan Of Discovery Of Suspected Pulmonary Tuberculosis In The Working Area Of Karang Mekar Puskesmas Center Banjarmasin In 2019. Jurnal Kesehatan Indonesia (The Indonesian Journal Of Health), 10(3), 2-7.

Widjanarko, B., Prabamurti, P. N., \& Widayat, E. (2018). Pengaruh Karakteristik, Pengetahuan Dan Sikap Petugas Pemegang Program Tuberkulosis Paru Puskesmas Terhadap Penemuan Suspek TB Paru Di Kabupaten Blora. Jurnal Promosi Kesehatan Indonesia, I(1), 41-52. Https://Doi.Org/Https://Doi.Org/10.14 710/Jpki.1.1.41-52 
JOURNAL OF PUBLIC HEALTH INOVATION

VOL. 02. NO. 01, DESEMBER 2021

DOI: $\underline{10.34305 / j p h i . v 2 i 1.345}$

Wijaya, I M. K. (2013). Pengetahuan,

Sikap Dan Motivasi Terhadap

Keaktifan Kader Dalam Pengendalian

Tuberkulosis. Jurnal Kesehatan

Masyarakat, 8(2), 119-127.

World Health Organization. (2020). Global Tuberculosis Report.
Ciptaan disebarluaskan di bawah Lisensi Creative Commons Atribusi-

NonKomersial-BerbagiSerupa 4.0 Internasional. 